\title{
PRÁTICAS CULTURAIS NO ENSINO DE PORTUGUÊS PARA ESTRANGEIROS
}

\author{
Cássia Regina Coutinho SOSSOLOTE ${ }^{1}$ \\ Flávia Maria de Aquino MARTINS ${ }^{2}$ \\ Leonardo Vicente VIVALDO ${ }^{3}$ \\ Luci Regina MUZZETI ${ }^{4}$ \\ Darbi Masson SUFICIER ${ }^{5}$
}

RESUMO: O artigo intitulado Práticas Culturais no Ensino de Português para Estrangeiros tem como objetivo divulgar ensaio docente voltado para o ensino de língua a alunos oriundos de Guiné Bissau para quem o Português de Portugal constitui língua oficial. Buscamos problematizar o curso ministrado a esses alunos com o objetivo de que se apropriassem de "recursos de expressão" para a sua aprovação em disciplinas que estavam cursando, no Brasil, no primeiro semestre da graduação em Letras em instituição de ensino superior.

PALAVRAS-CHAVE: Trabalho docente e práticas pedagógicas. Práticas culturais. Concepções sobre o ensino de línguas. Relação conteúdo e metodologia. Letramento.

\section{Introdução}

Tem-se como objetivo neste artigo apresentar experiência docente em relação ao ensino de Português para Estrangeiros tal como ocorreu em $2009^{6}$. Faremos o relato de projeto coordenado por docente responsável pelas disciplinas Prática de Ensino de Língua Materna I e Estágio Supervisionado de Prática de Ensino de Língua Portuguesa I, ministradas no $1^{\circ}$ semestre do ano letivo, e Prática de Ensino de Língua Materna II e

\footnotetext{
${ }^{1}$ UNESP - Universidade Estadual Paulista. Faculdade de Ciências e Letras - Departamento de Didática. Araraquara - SP - Brasil. 14800-901 - sosso@ fclar.unesp.br

${ }^{2}$ CENTRO PAUlA SOUZA. ETEC "Prof ${ }^{a}$ Anna de Oliveira Ferraz" - Rede de Ensino Municipal de Araraquara. Araraquara - SP - Brasil. 14801-180 - flavia.martins@etec.sp.gov.br

${ }^{3}$ Doutorando em Estudos Literários. UNESP - Universidade Estadual Paulista. Faculdade de Ciências e Letras - Pós-graduação em Estudos Literários. Araraquara - SP - Brasil. 14800-901 leovivaldo@yahoo.com.br

${ }^{4}$ UNESP - Universidade Estadual Paulista. Faculdade de Ciências e Letras - Departamento de Didática. Araraquara - SP - Brasil. 14800-901 - lucirm@fclar.unesp.br

${ }^{5}$ Doutorando em Educação Escolar. UNESP - Universidade Estadual Paulista. Faculdade de Ciências e Letras - Pós-graduação em Educação Escolar. Araraquara - SP - Brasil. 14800-901 darbimassonsuficier@hotmail.com

${ }^{6}$ Os alunos de Guiné Bissau puderam realizar sua graduação na Unesp em virtude do "Programa de Estudantes-Convênio de Graduação - PEC-G" que se destina à formação e qualificação de estudantes estrangeiros por meio de oferta de vagas gratuitas em cursos de graduação em Instituições de Ensino Superior - IES brasileiras. Cf. Artigo $1^{\circ}$, do Decreto n 7.948 (BRASIL, 2013).
} 
Estágio Supervisionado de Prática de Ensino de Língua Portuguesa II, oferecidas no segundo semestre em instituição de ensino superior.

É importante ressaltar que o projeto que será referido no espaço deste texto foi desenvolvido em parceria com alunos que estavam cursando tais disciplinas, que dele participaram assumindo atividades de regência das aulas de Português Língua Estrangeira (doravante PLE).

O curso foi oferecido a alunos oriundos de países africanos, particularmente, aos que vieram de Guiné Bissau para realizar a graduação em Letras, na Faculdade de Ciências e Letras, da Universidade Estadual Paulista "Júlio de Mesquita Filho", do Câmpus de Araraquara.

\section{Descrição do trabalho desenvolvido}

As disciplinas Prática de Ensino de Língua Materna I e Prática de Ensino de Língua Materna II são disciplinas que apresentam um conteúdo programático marcadamente teórico que permite discutir conteúdo(s), metodologia(s) e prática(s) de ensino de língua materna com base em diferentes paradigmas linguísticos.

Não se trata de replicar, nas disciplinas mencionadas, objetos de ensino que a cultura escolar próprias ao Ensino Fundamental e ao Ensino Médio legitimaram ao longo do tempo.

Com base nos conhecimentos, nos saberes produzidos em instituições de ensino superior (IES), pretendemos colocar em evidência, nas disciplinas mencionadas, o fato de que ensino e aprendizagem podem ganhar contornos e especificidades em função dos objetos de ensino objetivados por meio de teorias linguísticas filiadas a paradigmas científicos diferentes, organizados, por sua vez, em relação a práticas linguageiras como as "práticas de produção de textos", "práticas de leituras de texto" e "práticas de análise linguística" (GERALDI, 2010).

Não nos parecia, contudo, no primeiro momento em que entramos em contato com os nossos alunos estrangeiros, que seria possível, com base nos programas dessas disciplinas, organizarmos um curso voltado para o ensino de Português Língua Estrangeira (PLE), sem leituras específicas, próprias a este campo de conhecimento, embora sustentássemos posições de que teorias com grande alcance explicativo tivessem potencial para dar visibilidade a fenômenos presentes na organização e funcionamento das línguas naturais dos quais se parte no processo de ensino e 
aprendizagem de qualquer língua, conquanto o professor tenha domínio da língua estrangeira a ser ensinada.

Em virtude da concepção que orientava o nosso trabalho nas disciplinas em questão, considerávamos que, para além das diferenças no modo de organização e funcionamento das línguas quando se compara uma língua à outra, existem operações invariantes na constituição da significação, fato que rompe com a dicotomia sustentada por muitos teóricos de que objetos de ensino e metodologias alterar-se-iam a depender da língua ensinada: língua materna ou línguas estrangeiras. Por isso, aceitamos os desafios, no curso de Português Língua Estrangeira, de investir nas "práticas de produção de textos", "práticas de leitura de textos", e nas "práticas de análise linguística".

Cabe destacar que a situação inicial que vivenciamos em relação aos estrangeiros foi aquela em que estavam enfrentando dificuldades, sobretudo, em relação a disciplinas da área de Literatura que estavam cursando no primeiro ano do curso de Letras.

Diante das dificuldades dos alunos africanos, oferecemos a eles um curso que se destinava à leitura dos textos literários indicados pelos professores das disciplinas cursadas no $1^{\mathrm{o}}$ semestre de 2009. Nesse sentido, ora fizemos a leitura de textos, buscando oferecer ao aluno um intertexto relacionado ao autor, ao movimento literário, ao contexto sócio-histórico de produção da obra que estava sendo lida, ora a leitura de textos da crítica literária indicados pelos professores das disciplinas vinculadas ao campo de conhecimento da Literatura.

Podemos afirmar que a experiência com os alunos de Guiné Bissau foi enriquecedora, pois viemos a conhecer muitos aspectos sociais, políticos e culturais do país de origem desses alunos. Foram-nos dados, assim, elementos pelos próprios alunos para compreender a natureza das dificuldades que estavam apresentando em relação às diferentes disciplinas oferecidas no $1^{\circ}$ semestre, do $1^{\circ}$ ano, do curso de Letras, fato que excluía a possibilidade de responsabilizarmos os professores que as ministraram pelas suas dificuldades.

Alguns fatos nos chamaram a atenção.

Guiné Bissau, como muitos países africanos, foi colônia de Portugal até 1974. E enquanto colônia de Portugal, os indivíduos aprenderam a língua do colonizador em instituições escolares. Embora o foco de nosso trabalho não seja este, a questão da identidade em relação à língua do colonizador coloca-se, evidentemente, como questão 
a investigar, já que em espaços formais de comunicação o Português de Portugal constitui a língua oficial.

Tivemos conhecimento, além disso, do seguinte fato: no processo de alfabetização e de apropriação da língua do colonizador, os textos utilizados foram textos da história de Portugal. Encontramos uma explicação plausível para compreender a dificuldade encontrada pelos alunos nas disciplinas Literatura Brasileira, Literatura

\section{Portuguesa e Teoria da Literatura.}

Os alunos de Guiné Bissau, apesar de terem um domínio relativo do Português de Portugal, desconheciam os textos pertencentes à Literatura Portuguesa, desconhecimento que constituía um grande obstáculo para a compreensão da própria Literatura Brasileira, uma vez a Literatura Portuguesa constitui importante intertexto ${ }^{7}$ para a nossa literatura. A falta de familiaridade em relação aos recursos expressivos do texto literário colocava-se como um elemento de estranhamento e constituía, portanto, um obstáculo para a apropriação dos textos escritos que circulam em instituições universitárias, notadamente, no curso de Letras.

Pudemos constatar com base nos próprios depoimentos dos alunos que as dificuldades em relação ao Português de Portugal iam além de questões que envolvem o ensino e a aprendizagem da língua, uma vez que, nos espaços não-formais, o crioulo constitui a língua que os falantes usavam, a língua por meio da qual interagiam. Este fato pôde ser observado quando os alunos africanos conversavam entre si em nossa Faculdade. As interações eram mediadas pelo crioulo, sua língua materna ${ }^{8}$.

Durante os cursos, levantamos outra hipótese, a de que os alunos de Guiné Bissau tinham o domínio do Português de Portugal, sobretudo, em relação à modalidade oral. Além disso, constatamos um fato comum no processo de escolarização dos alunos de Guiné Bissau e dos alunos brasileiros: o ensino da Nomenclatura Gramatical.

\footnotetext{
${ }^{7}$ Para Charaudeau e Maingueneau, (2006, p.288, grifo do autor), "[...] o termo intertexto designa ao mesmo tempo uma propriedade constitutiva de qualquer texto e o conjunto das relações explícitas ou implícitas que um texto ou um grupo de textos determinado mantém com outros textos. Na primeira acepção, é uma variante de interdiscursividade."

${ }^{8}$ Segundo Trask (2004, p.70-71, grifo do autor), o crioulo é “[...] uma língua que deriva de um pídgin. Um pídgin não é uma língua natural, é apenas um sistema de comunicação rudimentar, alinhavado por pessoas que não tem uma língua comum. Quando um pídgin se estabelece numa sociedade multilíngüe, então pode muito bem chegar um momento em que aparece uma geração de crianças que dispõem apenas do pídgin para falar entre si. Nesse caso, quase inevitavelmente, as crianças transformam o pídgin numa verdadeira língua, completada por um vocabulário amplo e um rico sistema gramatical. Essa nova língua cultural é um crioulo, e as crianças que o inventaram são os principais falantes nativos desse crioulo. $\mathrm{O}$ processo pelo qual se transforma um pídgin em um crioulo é a crioulização (creolization) [...]".
} 
Breve parêntese. O reconhecimento de que os alunos tinham maior familiaridade com a modalidade oral do Português de Portugal e de que a metodologia de ensino estava centrada na classificação dos constituintes da língua ocorreu durante a leitura de um texto indicado por um dos professores de literatura no primeiro semestre, do primeiro ano. A pergunta formulada por um dos alunos aos estagiários que participaram do projeto dizia respeito ao significado da palavra pressuposto, dúvida que foi formulada por meio da seguinte pergunta ao professor: - Pressuposto é um substantivo comum ou próprio?

Diante da pergunta feita, chegamos à seguinte conclusão. Dada a forte ocorrência desta palavra em textos escritos, era plausível levantar a hipótese de que o domínio da língua escrita por alguns alunos de Guiné Bissau ficava a desejar bem como os modos de leitura dos textos a que tiveram acesso. Os alunos não conseguiam levar em consideração a relação que os constituintes estabeleciam entre si no interior do enunciado, fato que tornava difícil levantar hipóteses a respeito do significado das palavras.

Em decorrência da experiência relatada pelos alunos em relação à "aquisição" do Português de Portugal, entendemos a insistência manifestada por aqueles que fizeram o curso conosco durante o Estágio Supervisionado de Prática de Ensino de Língua Portuguesa I de, não somente compreender os textos de literatura indicados pelos professores das disciplinas que estavam cursando, como também de vir a ter aulas de "gramática", principalmente, aulas que tivessem como objetivo central apresentar o Novo Acordo Ortográfico sancionado em 2009, no Brasil, e imposto como obrigatório na elaboração de textos escritos a partir de 01/01/2013. Fecha-se parêntese.

Em relação ao segundo semestre do Estágio Supervisionado de Prática de Ensino de Língua Portuguesa II, é preciso dizer que o curso proposto para ser ministrado aos nossos alunos africanos foi completamente revisto, já que alguns alunos acabaram fazendo a opção pelos cursos de Ciências Sociais, Administração Pública e Economia. Além disso, já havia a procura pelo curso de PLE por alunos de outros cursos que tinham uma história de aprovação e não de reprovação como aconteceu com os alunos de Guiné Bissau que chegaram a Araraquara em 2009.

Buscando desvincularmo-nos dos programas do curso de Letras durante a preparação de curso de extensão oferecido no segundo semestre, priorizamos a seleção de textos literários bem como a seleção de filmes, documentários e áudio-livros. 
Observe o leitor que continuamos a trabalhar com textos literários agora sob outra perspectiva. Ao invés de propormos um curso de natureza instrumental relacionado às disciplinas nas quais os alunos estavam matriculados, era necessário romper com a formalidade dos modos de leitura, dos modos de abordagem do texto, geralmente voltadas para a avaliação do desempenho dos alunos. No caso dos estrangeiros, a sistematicidade em relação aos objetos de ensino acaba se acentuando ainda mais, quando se busca identificar o grau de proficiência dos alunos em língua estrangeira: o Português do Brasil.

Consideramos imprescindível que o aluno estabelecesse relações de familiaridade com o texto literário, em virtude do fato de a Literatura ser um dos campos de conhecimento da área de Letras cujos pesquisadores têm como objetivo compreender as propriedades estéticas dos textos que pertencem a esse campo.

A densidade dos textos literários, dos recursos de expressão que se reiteram em sua composição, pareceu-nos oportuna para ampliar a imagem dos alunos estrangeiros em relação ao Português do Brasil e as possibilidades de expressão recorrentes no texto literário. Metáfora; comparação; metonímia, sinédoque; catacrese; antonomásia; sinestesia; zeugma; elipse; assíndeto; polissíndeto; aliteração; pleonasmo; hipérbato; silepse; epíteto; antítese; paradoxo; antífrase ou ironia; eufemismo; hipérbole; apóstrofe; clímax ou gradação; prosopopeia; onomatopeia (SAVIOLI, 2007) constituem recursos para o processo de referenciação. Como muitas "figuras de linguagem" podem estabelecer relações anafóricas ou catafóricas com outras expressões presentes no interior $\operatorname{do}(\mathrm{s})$ enunciado(s), poderíamos, ao mesmo tempo, orientar os modos de leitura dos textos dos alunos de modo a destacar os processos de construção da significação no interior do texto. No trabalho que realizamos, consideramos imprescindível não perder de vista o fato de que a relação que as expressões estabelecem no interior do texto são indeterminadas, embora tragam rastros dos significados de maior ocorrência. Disto decorre a necessidade de levar em consideração a relação entre a(s) parte(s) e o todo.

Pensamos entre outros caminhos para orientar a compreensão dos textos literários pelos estrangeiros. A primeira foi oferecer-lhes intertexto para a compreensão de tais figuras quando os enunciados fossem insuficientes para deixar entrever os significados veiculados por meio dos recursos literários em questão, pois a compreensão do significado "[...] vai muito além do que é dito explicitamente e requer a consideração de elementos que vão desde informações dadas pelo contexto próximo até 
considerações de ordem mais ampla como lugares sociais, ideologias, história cultural, etc.” (GERALDI, 2010, p.71). Neste sentido, a indeterminação do texto pode estar ligada também ao desconhecimento do sentido das formas construídas historicamente.

Outra alternativa seria nos valer de textos que viessem a desempenhar função metadiscursiva para a compreensão dos significados construídos nos textos literários que se apresentam ao falante não nativo com relativa opacidade. Procedemos dessa forma, do ponto de vista metodológico, com o objetivo de relacionar "língua" e "cultura".

Sabe-se, no momento atual, a ênfase dada aos gêneros discursivos no ensino de língua materna que passou a constituir um dos objetos de ensino. $\mathrm{Na}$ época, pareceu-nos que o fato de os estrangeiros estarem em situação de imersão lhes daria elementos para a composição de textos primários, nas palavras de Bakhtin (2000). Além disso, consideramos que poderíamos incorrer em pragmatismo exacerbado, que não traria nenhuma contribuição para a estruturação do capital linguístico e do capital cultural, se organizássemos um curso de Português para Estrangeiros com base nos gêneros discursivos primários que circulam socialmente e que se materializam por meio da modalidade oral.

Com base em publicação datada de 2010, de João Wanderley Geraldi, pudemos reafirmar nossas posições acerca dos princípios que nortearam o curso de extensão oferecido aos estrangeiros oriundos de Guiné Bissau.

Geraldi (2010), ao refletir sobre os objetos de ensino ligados à leitura, oferecenos informações que talvez já tenham caído no esquecimento. Diz ele,

Desde a década de 1960 predomina o ponto de vista de que é necessário diversificar os gêneros de discurso em circulação na sala de aula, incluindo-se desde propagandas, histórias em quadrinhos, notícias e reportagens jornalísticas até a presença hoje quase tímida do gênero poético. (GERALDI, 2010, p.58).

Buscando encontrar respostas para a falta de autoria nos textos produzidos pelos alunos, dirá o autor que

[...] o meritório movimento de diversificação de textos de leitura [e de gêneros propostos para a produção] acabou por diminuir excessivamente a presença do texto literário, especialmente do texto poético, nas salas de aula [em certo sentido, nesta segunda metade do 
século XX acabamos realizando o projeto de expulsão da poesia proposto por Platão]. Este movimento de diversificação não pode ser simplesmente atribuído à complexidade das atividades humanas que levam à multiplicidade de gêneros literários discursivos (Bakhtin, 1952/1953), mas há um projeto de sociedade e de ciência mais profundo que sustentou o sucesso deste movimento. (GERALDI, 2010, p.66-67).

Apesar das considerações relevantes feitas por este autor a respeito do modo como o programa "epistemológico" na área das ciências humanas interferiu nos objetos de ensino ligados à leitura, encontrarmos em Geraldi (2010) elementos para reafirmar nossas convicções quando diz que

\begin{abstract}
Uma questão que poderia ser posta [em relação à autoria dos textos produzidos pelos alunos] diz respeito ao convívio com o gênero literário como caminho necessário a ser percorrido se se pretende desenvolver a capacidade de expressão mesmo quando o autor é chamado/convocado a produzir um texto argumentativo. (GERALDI, 2010, p.66).
\end{abstract}

Visando trabalhar com os textos secundários que se caracterizam pela sua complexidade em virtude de sua forma de organização e de seus contextos de ocorrência, pois se tratam de textos científicos, literários, filosóficos, foram selecionados textos literários com base nos quais foram produzidos filmes, documentários, áudio-livros, a fim de que estes textos fossem trabalhados concomitantemente às obras selecionadas de natureza literária.

É preciso dizer que a primeira motivação que tivemos para selecionar textos literários para o curso de extensão que seria oferecido esteve relacionada ao desejo de estabelecer relações dialógicas menos assimétricas com os alunos estrangeiros. $\mathrm{O}$ fato de o Brasil e de Guiné Bissau terem sido colônias de Portugal motivou-nos a selecionar textos que tratassem de questões relacionadas à colonização. Esta opção metodológica, em nosso entendimento, abriu caminho para minimizar a artificialidade das situações de interlocução que caracterizam o ensino de língua em contextos formais como a escola.

O segundo motivo que nos levou a selecionar textos literários no curso ministrado está relacionado a pesquisas realizadas pela $\operatorname{Prof}^{a} \operatorname{Dr}^{a}$ Luci Regina Muzzeti que se organizam com base no referencial teórico de Pierre Bourdieu. Os trabalhos desenvolvidos em parceria com a professora no projeto Ler é Viver, que coordena, no qual atuamos como professora colaboradora, levou-nos a compreender a relevância das 
categorias bourdeunianas para a explicação "das desigualdades de rendimento dos agentes escolares frente ao sistema de ensino".

O conceito de capital cultural e o de ethos (BOURDIEU apud MUZZETI, 2013), para nós, é particularmente importante, pelo alcance explicativo que apresentam tanto em relação ao processo de apropriação de uma determinada herança cultural pelos indivíduos como para a (re)interpretação de afirmações oriundas do senso comum formuladas pelos representantes do sistema de ensino que se restringem, por sua vez, a constatações sobre o êxito e o fracasso de agentes escolares no interior do sistema de ensino.

Embora tendo consciência de que estamos forjando uma situação que consiste em isolar uma categoria em detrimento da discussão de todas as outras que dão materialidade à teoria bourdiniana, o conceito de capital cultural, para nós, é importante, pois Pierre Bourdieu (apud MUZZETI, 2013) definiu cultura em relação ao conceito de fração de classe.

Segundo Bourdieu (apud MUZZETI, 2013, p.6), “[...] cada família transmite à sua descendência uma herança cultural. Essa herança puramente social é constituída pelo capital cultural e pelo ethos que difere em cada fração de classe, segundo seu meio de pertencimento [...]".

O fato de Pierre Bourdieu não operar com um conceito abstrato de cultura tornou possível relacionar o desempenho dos agentes escolares em relação à cultura da fração de classe legitimada socialmente.

Para Bourdieu (apud MUZZETI, 2013, p.8, grifo do autor)

A cultura da elite é tão próxima da cultura escolar que as crianças originárias de um meio burguês (ou, a fortiori, camponês e operário) não podem adquirir, senão penosamente, o que é herdado pelos filhos das classes cultivadas: o estilo, o bom gosto, o talento, em síntese, essas atitudes e aptidões que só parecem naturais e naturalmente exigíveis dos membros da classe cultivada, porque constituem a "cultura" [...] dessa classe. Não recebendo de suas famílias nada que lhes possa servir em sua atividade escolar, a não ser uma espécie de boa vontade cultural vazia, os filhos das classes médias são forçados a tudo esperar e a tudo receber da escola, e sujeitos, ainda por cima, a ser repreendidos pela escola por suas condutas por demais "escolares". 
Disso decorre afirmação feita pelo autor de que a forma de apreensão da cultura legitimada pela escola é qualitativamente diferente se se tomar como referência os modos de ser das diferentes frações de classe.

Enquanto a familiaridade dos filhos da elite com os bens culturais ${ }^{9}$ considerados legítimos são adquiridos no ambiente familiar, sem qualquer esforço metódico, os filhos das outras frações de classe só adquirem penosamente "[...] a proeza verbal, a relação de intimidade com o saber próprios da classe dominante.” (MUZZETI, 2013. p.7).

Pudemos validar as concepções de Muzzeti (2013), formuladas com base no referencial teórico de Pierre Bourdieu, durante o curso de extensão ministrado no segundo semestre de 2009 a um grupo maior de alunos oriundos de países africanos. Dentre aqueles que vieram de Guiné Bissau, um se destacava pelo fato de alguns membros da família falarem o Português de Portugal. Havia, nessa família, inclusive, um professor de Português. Como a relação com o Português de Portugal foi cultivada no interior da família tanto quanto a relação com os textos legitimados pela cultura dominante, a literatura constituiu para esse aluno um problema de fácil solução.

\section{Lições aprendidas}

A primeira lição aprendida é a de que seria impossível em curso de extensão ministrado em instituições de ensino superior adotarmos métodos para a apropriação do patrimônio cultural legitimado pela escola em que não estivesse implicado posturas sistemáticas visando à apropriação do saber ${ }^{10}$.

Segunda lição. Embora alguns alunos do curso de extensão ministrado em 2009 tenham se sentido entediados diante das opções que fizemos, buscamos "ensinar Português para Estrangeiros" de forma a priorizar as práticas discursivo-culturais, legitimadas socialmente, que se materializam por meio da variante culta.

Terceira lição. Em tempos de internacionalização, devemos nos perguntar se seria legítimo estabelecer convênios, incentivando a vinda de alunos ainda que se revelassem capaz de realizar análises linguísticas da Língua Portuguesa, sem ter relativa familiaridade com as práticas linguageiras voltadas para a leitura e para a produção de textos.

\footnotetext{
${ }^{9}$ Para Bourdieu (apud MUZZETI, 2013, p.8-9), os bens culturais considerados legítimos são “[...] os bens simbólicos que uma formação social seleciona como dignos de serem possuídos e desejados.” e que são representados pela leitura, pela frequência a teatros, a museus, a cinemas, etc.

${ }^{10}$ Confira nas páginas de 146 a 150 deste artigo.
} 
A quarta lição apreendida está voltada exclusivamente para o curso de Letras. Seria o curso de Letras uma opção para alunos que não possuem familiaridade com o texto literário? Afinal, é impossível dedicar-se a investigação a respeito das propriedades estéticas do texto literário, levando-se em consideração os cânones da crítica literária brasileira, sem que os indivíduos tenham tido experiências prévias de leitura dos clássicos da literatura brasileira e portuguesa.

\section{CULTURAL PRACTICES IN TEACHING PORTUGUESE FOR FOREIGNERS}

ABSTRACT: The article entitled Cultural Practices in Teaching Portuguese for Foreigners aims to disseminate teaching practices facing the language teaching to students from Guinea Bissau or whom the Portuguese of Portugal is the official language. We seek to problematize the course given to those students with the purpose of appropriating the "resources of expression" for approval in subjects who were enrolled in Brazil in the first half of undergraduate Letras course in a higher education institution.

KEYWORDS: Teachers' work and teaching practices. Cultural practices. Conceptions of language teaching. Relationship content and methodology. Literacy.

\section{REFERÊNCIAS}

BAKHTIN, M. Estética a criação verbal. Tradução de Maria Ermantina Galvão G. Pereira. 3.ed. São Paulo: Martins Fontes, 2000.

BRASIL. Decreto n.7.948, de 12 de março de 2013. Dispõe sobre o Programa de Estudantes-Convênio de Graduação - PEC-G. Diário Oficial da União: República Federativa do Brasil, Brasília, DF, 13 mar. 2013. Disponível em:< http://www.planalto.gov.br/ccivil_03/_Ato2011-2014/2013/Decreto/D7948.htm>. Acesso em: 10 maio 2014.

CHARAUDEAU, P.; MAINGUENENEAU, D. Dicionário de análise do discurso. Tradução de Fabiana Komesu. 2.ed. São Paulo: Contexto, 2006.

GERALDI, J. W. A aula como acontecimento. São Carlos: Pedro \& João Ed., 2010.

MUZZETI, L. R. Relatório trienal referente ao período compreendido entre 2010 a 2012. Araraquara: Faculdade de Ciências e Letras da Unesp, 2013.

SAVIOLI, F. P. Gramática em 44 lições com mais de 1700 exercícios. 14.ed. São Paulo: Ática, 2007.

TRASK, R. L. Dicionário de linguagem e linguística. Tradução de Rodolfo Ilari. São Paulo: Contexto, 2004. 